\author{
Д. О. Добровольский \\ ${ }^{1}$ Институт русского языка им. В. В. Виноградова РАН \\ Институт языкознания РАН \\ Стокгольмский университет \\ ${ }^{2}$ Институт языкознания РАН \\ ФИЦ «Информатика и управление» РАН \\ (Россия, Москва) \\ dobrovolskij@gmail.com,anna.zalizniak@gmail.com
}

\title{
РУССКИЕ КОНСТРУКЦИИ С ПОТЕНЦИАЛЬНО МОДАЛЬНЫМ ЗНАЧЕНИЕМ ПО ДАННЫМ ПАРАЛЛЕЛЬНЫХ КОРПУСОВ*
}

В статье предлагается метод выявления единиц (конструкций) русского языка с потенциально модальным значением путем анализа способов передачи в русском переводе значений, выраженных в немецком оригинале конструкциями с модальными глаголами, составляющими в этом языке отчетливый семантико-грамматический класс. В статье рассматриваются только базовые модальные значения возможности и необходимости - в онтологическом, деонтическом и эпистемическом вариантах. Полученное таким образом множество реально встретившихся в переводных русских текстах функциональных эквивалентов для немецких конструкций с модальными глаголами включает ряд единиц, способность которых выражать модальное значение не фиксируется в словарях. В статье предлагается предварительный список таких единиц, для которых формулируется вариант толкования, содержащий модальный компонент, приводятся примеры соответствующих межъязыковых соответствий.

Ключевые слова: модальность, модальное значение, русский язык, немецкий язык, семантика, перевод.

Анализ переводных соответствий как способ изучения семантики языковых единиц широко используется в современной лингвистике [ср., в частности: Johansson, Oksefjell 1998; Noël 2003; Bonola 2017]. В данном исследовании

* Работа выполнена при частичной поддержке РФФИ, грант №20-012-00166 «Исследование семантики модальных конструкций по данным немецко-русского параллельного корпуса» и № 19-012-00505 «Дискурсивные единицы русского языка: семантика и механизмы прагматикализации». 
применялся «монофокусный» метод контрастивного анализа (в [Зализняк 2015а] он был назван «унидирекциональным»), суть которого состоит в том, что сопоставление оригинального текста с его переводом используется как инструмент анализа интересующей нас единицы одного из сопоставляемых языков: перевод на другой язык рассматривается как своего рода толкование для анализируемой единицы языка оригинала — и наоборот, исследование «стимулов» появления той или иной языковой единицы в переводе может выявить неочевидные компоненты значения этой единицы. В нашей работе этот метод был использован для выявления множества лексических единиц и конструкций русского языка, которые в тех или иных контекстных условиях оказываются способны передавать модальное значение, выраженное в предложении оригинала конструкцией с одним из модальных глаголов немецкого языка. Полученное таким образом множество реально встретившихся в переводных русских текстах функциональных эквивалентов для немецких конструкций с модальными глаголами включает ряд единиц, способность которых выражать модальное значение априори не очевидна ${ }^{1}$. Выявление множества русских конструкций с потенциально модальным значением является одной из задач проекта «Исследование семантики модальных конструкций по данным немецко-русского параллельного корпуса», главная цель которого - уточнение семантики немецких модальных глаголов с помощью анализа их русских переводных соответствий, реально используемых профессиональными переводчиками ${ }^{2}$.

В отличие от немецкого языка, где существует особый грамматический класс модальных глаголов (können, dürfen, müssen, sollen, wollen, mögen), каждый из которых имеет целый спектр значений (в том числе не модальных), в русском языке есть лишь два модальных глагола с семантическим субъектом в позиции подлежащего - мочь и хотеть; все остальные значения передаются предикативами или безличными глаголами․

${ }^{1}$ Гарантией наличия в русском предложении собственно модального значения служит производимая нами (по [НРС]) идентификация значения немецкого глагола в предложении оригинала плюс положительная оценка адекватности перевода. Производные не собственно модальные значения немецких модальных глаголов (значение уступки, недоверия к высказанному мнению и др.) и способы их передачи при переводе на русский язык составляют предмет отдельного исследования и здесь рассматриваться не будут.

2 О создаваемой в рамках данного проекта базе данных переводных соответствий, извлеченных из немецко-русского параллельного корпуса [НКРЯ], см. подробнее в [Добровольский, Зализняк 2018].

3 Так, в [РГ 1980/2: 215] приводится следующий список лексических средств выражения «объективной модальности»: можно, нельзя, надо, нужно, необходимо, должен, обязан, может, хочет, желает, следует (в значении 'надо'), не годится (в значении 'не следует'), надлежит, подобает. И этот список является далеко не полным. Что касается «субъективной модальности», то к этой категории в [РГ 1980] относится очень широкий круг значений, включающий весь спектр субъективных оценок. Нас интересуют прежде всего те способы выражения модальности (как «объективной», так и «субъективной»), которые не фиксировались как таковые в традиционных описаниях. 
Ю. Д. Апресян выделяет среди системообразующих смыслов три вида модальных значений: возможность, долженствование и намерение [Апресян 2005: 19]. Однако поскольку отправной точкой данного исследования являются немецкие модальные глаголы, а для глагола wollen значения намерения и желания слабо дифференцированы, модальное значение намерения мы здесь исключаем из рассмотрения. В данной работе речь будет идти лишь о значениях н е о б х о д и м о с т и (д о л же н с т в о в ан и я) и - в меньшей степени - в о з м жн о с т и - в онтологическом, деонтическом и эпистемическом вариантах. В онтологическом и деонтическом вариантах эти значения составляют базовые (восходящие к Аристотелю) типы модального значения, в эпистемическом - относятся к оценочной, или субъективной, модальности [ср.: Падучева 2016], для обозначения которой используется также термин эпистемическая модальность [ср.: Плунгян 2011: 426]. Значения возможности и необходимости мы будем называть собственно модальнылми. В предлагаемых нами экспликациях значения русских языковых единиц, выступающих в роли эквивалента немецкой конструкции с модальным глаголом, модальная составляющая выделена малыми прописными. Вариант модального значения помечен индексами: $o$ - онтологический, $\partial$ - деонтический, э- эпистемический.

В приводимых ниже примерах вида «немецкий оригинал - русский перевод» полужирным курсивом в немецком предложении выделен модальный глагол, в русском переводе - соответствующий ему носитель модального значения; cветлым курсивом в обеих частях примера выделен релевантный контекст. Все примеры взяты из немецкого параллельного подкорпуса [НКРЯ].

\section{Bместо [Ngen]}

(1) $\quad<\ldots>$ was ihm zur Zufriedenheit hätte gereichen sollen, flößte ihm Grauen ein. (Friedrich Dürrenmatt. Der Verdacht. 1953) -

$<\ldots>$ вместо удовлетворения он испытывал ужас (Фридрих Дюрренматт. Подозрение / Н. Савинков. 1990) 4 .

В примере (1) в качестве единицы перевода берется не отдельный модальный глагол и даже не его непосредственное окружение (зависимый инфинитив с заполненными валентностями), а целая клауза was ihm zur Zufriedenheit hätte gereichen sollen. Модальное значение, выражаемое в немецком языке плюсквамперфектной формой конъюнктива модального глагола sollen, в [НРC] описывается следующим образом: «только в формах praet conj и pqp conj следовало (бы), нужно было (бы), должно было (быl) (по мнению говорящего)». При буквальном (и в какой-то степени искусственном) переводе это предложение могло бы выглядеть так: То, что должно было бы дать ему удовлетворение, наполнило его ужасом. Переводчик, однако, воспользовался иной конструкцией, не содержащей модального слова, но при этом достаточно полно

${ }^{4}$ В контекстах из [НКРЯ] сохранена орфография оригинала. Часто это орфографическая норма до реформ правописания 1996, 2005 и 2006 гг. 
отражающей смысл исходной немецкой фразы, - предложной группой вместо удовлетворения. Этот способ передачи модального значения не учтен ни в одном описании русско-немецких соответствий в области способов выражения модальности.

Семантика предлога вместо действительно включает модальную составляющую, ср. толкование в [AC: 165]: «A1 вместо A2. Указывает на то, что в данном случае должна была иметь место ситуация А2 или использоваться объект А2, но имеет место ситуация А1 или используется объект А1». Таким образом, в значение предлога вместо входит компонент должно дыло. Однако этот предлог не включается в список средств выражения модальности в русском языке; дело, по-видимому, в том, что в русской грамматической традиции до сих пор не ставилась задача выявления множества языковых единиц, в значении которых содержится модальная составляющая. Между тем эта задача представляет как теоретический, так и практический интерес.

\section{2. [Ndat] (не) дано / суждено [Vinf]}

Вводя описание некоторого события при помощи этой конструкции, говорящий выражает представление о том, что его наступление (как бы) определено некоей высшей силой — и тем самым оно должно дыло наступить. В немецком оригинале здесь могут быть глаголы sollen или dürfen.

(2) Aber dahin sollte es nie kommen, denn Grenouille, der an der Place de Greve am Ufer stand und mehrmals einen kleinen Fetzen Meerwind, den er in die Nase bekommen hatte, aus- und einatmete, sollte das Meer, das eigentliche Meer, den großen Ozean, der im Westen lag, in seinem Leben niemals sehen (Patrick Süskind. Das Parfum: Die Geschichte eines Mörders. 1985) -

Но этому не дано было сбыться, ибо Греную, стоявшему на Гревской площади на берегу Сены и многократно вдыхавшему маленький обрывок морского ветра, попавший ему на нос, не суждено было никогда в жизни увидеть море, настоящее море, великий океан, лежащий на западе (Патрик Зюскинд. Парфюмер: История одного убийцы / Э. Венгерова. 1992);

(3) Ich gäbe alle heiteren Tage, die ich je gehabt, samt allen Verliebtheiten und samt meinen Dichterplänen, wenn ich dafür noch einmal so ins Allerheiligste hineinsehen dürfte wie in jener Zeit (Hermann Hesse. Peter Camenzind. 1904) Я отдал бы все светлые дни, прожитые мною когда-либо, вместе со всеми влюбленностями и всеми поэтическими мечтами в придачу, если бы за это мне дано было еще раз заглянуть в святая святых, как в то славное время (Герман Гессе. Петер Каменцинд / Р. Эйвадис. 1995).

\section{3. [Ndat] nopa [Vinf]}

Предикатив пора относится к ядерной части русского модального лексикона: $X$-y пора делать нечто означает, что (по мнению говорящего) $\mathrm{X}$ должЕН д это сделать, причем немедленно. В немецком оригинале в этом случае используется 
глагол müssen (ср. примеры 4-5), хотя возможны также контексты c sollen (ср. примеры 6-7).

(4) „Wir müssen Abschied voneinander nehmen, Kommissar.“ Der Riese stand auf. (Friedrich Dürrenmatt. Der Verdacht. 1953) -

- Ну что ж, комиссар, нам пора прощаться, — сказал гигант и встал (Фридрих Дюрренматт. Подозрение / Н. Савинков. 1990);

(5) $<\ldots>$ jetzt mußt du gehen, es ist gleich halb acht, und die ersten Kinder kommen. (Heinrich Böll. Ansichten eines Clowns. 1963) -

<..> тебе пора идти, уже почти половина восьмого, вот-вот явятся дети (Генрих Бёлль. Глазами клоуна / Л. Черная. 1964);

(6) Nachdem Gerda Buddenbrook ihn ein wenig hatte gewähren lassen, beschloß sie, daß er Klavierunterricht bekommen sollte (Thomas Mann. Buddenbrooks. 18961900) -

Позволив ему некоторое время так позабавляться, Герда решила, что мальчику пора учиться музыке (Томас Манн. Будденброки / Н. Ман. 1953);

(7) Er war schon längst mit allem fertig und lag nun faul auf der gleichen Stelle, als die Schwester zum Zeichen, daß er sich zurückziehen solle, langsam den Schlüssel umdrehte (Franz Kafka. Die Verwandlung. 1912) -

Он давно уже управился с едой и лениво лежал на том же месте, где ел, когда сестра в знак того, что ему пора удалиться, медленно повернула ключ (Франц Кафка. Превращение / С. Апт. 1964).

\section{Bom-rom [Vfut]}

Единица вот-вот, так же как и пора, связана с фиксацией события на временно́й оси: она указывает на то, что что-то должно эроизойти в ближайшем будущем. В немецком оригинале в этом случае может быть употреблен глагол müssen, а также wollen (в значении предстояния). Ср.:

(8) Und wie damals wurde ihm unendlich bang und angst, und er glaubte, ersticken $\mathrm{zu}$ müssen (Patrick Süskind. Das Parfum: Die Geschichte eines Mörders. 1985) И как тогда, он испытал бесконечный ужас и страх и подумал, что вот-вот задохнется (Патрик Зюскинд. Парфюмер: История одного убийцы / Э. Венгерова. 1992);

(9) Zwei- oder dreimal, an Nachmittagen, da es aussah, als ob die Sonne hervorkommen wollte, erschienen zur Table d'hôte ein paar Bekannte aus der Stadt, die sich gern ein wenig unabhängig von ihren Angehörigen unterhielten (Thomas Mann. Buddenbrooks. 1896-1900) -

Раза два или три, когда казалось, что вот-вот проглянет солнышко, из города приезжал кое-кто из знакомых, любителей поразвлечься вдали от семьи (Томас Манн. Будденброки / Н. Ман. 1953). 


\section{5. Лучше [Vinf] / лучше бы [Vpast]}

Наличие модальной составляющей в этой конструкции вытекает из того, что

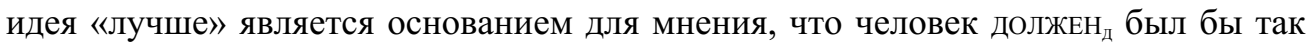
сделать. В немецком языке этот смысл передается глаголом sollen (в индикативе или конъюнктиве).

(10) Wohl nach schon viertelstündiger Arbeit sagte die Mutter, man solle den Kasten doch lieber hier lassen (Franz Kafka. Die Verwandlung. 1912) -

Когда они провозились уже с четверть часа, мать сказала, что лучше оставить сундук там, где он стоит (Франц Кафка. Превращение / С. Апт. 1964);

(11) Ich dachte schon, wir sollten das Geld lieber aufheben und zur Bank bringen (Erich Kästner. Emil und die Detektive. 1929) -

Я думаю, лучше деньги эти сберечь, положить в банк (Эрих Кестнер. Эмиль и сыщики / Л. Лунгина. 1971);

(12) Sie sagte nichts, nickte aber, und ich konnte genug von ihrem Gesicht sehen, um zu wissen, dass sie die Tränen zurückhielt. Sie hätte weinen sollen, heftig und lange (Heinrich Böll. Ansichten eines Clowns. 1963) -

Она промолчала, но кивнула, я увидел только краешек ее лица и все же понял, что она с трудом удерживается от слез. Лучше бы она заплакала - бурно, навзрыд (Генрих Бёлль. Глазами клоуна / Л.Черная. 1964);

(13) „Erstaunt“, schrie ich, „Sie sollten erstaunt sein über die gedankenlosen Hunde, die ihre Frauen einfach als rechtmäßigen Besitz betrachten..." (Heinrich Böll. Ansichten eines Clowns. 1963) -

— Поражены, — закричал я, — лучше бы вы поражались тупоголовым животным, для которых их жены - не что иное, как законная собственность... (Генрих Бёлль. Глазами клоуна / Л.Черная. 1964).

\section{6. Напрасно [Vpast]}

Напрасно (в данном типе употребления) означает фактически 'кто-л. должЕн Был поступить иначе'; ср. толкование оценочного значения слова напрасно в [Зализняк 2006: 121]: «некоторое $\mathrm{R}$, которое могло бы быть вместо Р, лучше, чем $\mathrm{P}$ (в частном случае $\mathrm{P}=$ отсутствие $\mathrm{R}$ )». Обратим внимание на то, что здесь присутствует как идея «лучше», так и идея «вместо» (ср. пункты 1, 5). В немецком это sollen в плюсквамперфекте конъюнктива и всегда с отрицанием, поскольку именно так передается идея, что нечто было бы лучше, но оно не случилось.

(14) „Man hätte ihn nicht so frei herumlaufen lassen sollen“, sagte der Student, als wolle er der Frau eine Erklärung für Ks beleidigende Rede geben, „,es war ein Missgriff" (Franz Kafka. Der Prozess. 1914) -

Напрасно ему разрешили гулять на свободе, - сказал студент, словно хотел объяснить женщине обидные слова К., — это несомненный промах (Франц Кафка. Процесс / Р. Райт-Ковалева. 1965); 
(15) Ich hätte Ihnen überhaupt nichts sagen sollen (Gustav Meyrink. Der Golem. 1914) -

Я напрасно вам все это говорила (Густав Майринк. Голем / Д. Выгодский. 1922).

\section{Cmóum [Vinf]}

Конструкция со словом сто́ит также выражает оценку, включающую модальный компонент. Можно сказать, что конструкция со словом стоит представляет собой «смягченное» должен чае, когда стоит употреблено в вопросительном предложении, выражающем сомнение (ср. примеры (17) и (18)), оно квазисинонимично вопросу с нужно ли.

(16) Ein schönes Fest soll man nicht stören (Friedrich Dürrenmatt. Der Verdacht. 1953) -

Не стоит портить праздник (Фридрих Дюрренматт. Подозрение / Н. Савинков. 1990);

(17) Ich überlegte auch, ob ich wirklich die Lauretanische Litanei singen sollte; besser nicht: es könnte einer auf die Idee kommen, mich für einen Katholiken zu halten... (Heinrich Böll. Ansichten eines Clowns. 1963) -

Я размышлял также - cmoum ли мне петь литанию деве Марии, пожалуй, не стоит, люди могут подумать, что я католик... (Генрих Бёлль. Глазами клоуна / Л.Черная. 1964);

(18) Wollte er nur überlegen, ob er den Kampf aufnehmen solle oder nicht? (Friedrich Dürrenmatt. Justiz. 1985) -

Хотел для себя решить вопрос, стоит ему вступать в борьбу или нет? (Фридрих Дюрренматт. Правосудие / С. Фридлянд. 1988).

\section{Bnopy [Vinf]}

Слово впору выражает следующую сложную установку по отношению к действию, обозначенному подчиненным инфинитивом: 'на основании своей оценки имеющей место ситуации говорящий заключает, что он должен некоторый экстраординарный и, возможно, до какой-то степени абсурдный поступок (однако совершать его, скорее всего, не собирается)'s. В немецком оригинале могут быть все основные модальные глаголы: sollen, können, müssen, mögen (обычно в форме конъюнктива).

(19) „Der soll den Bürgermeister zum Gevatter haben!“ hat der Konsul gerufen... (Thomas Mann. Buddenbrooks. 1896-1900) -

— Тут уж впору звать в крестные самого бургомистра! — воскликнул консул (Томас Манн. Будденброки / Н. Ман. 1953);

${ }^{5}$ Ср. несколько иное толкование в [Урысон 2016: 56]. 
(20) Austausch der Arbeits- oder Wohnplätze $<\ldots>$ es wäre so still auf den Strassenkreuzungen, dass sie dort Mensch-ärgere-dich-nicht spielen könnten (Heinrich Böll. Ansichten eines Clowns. 1963) -

Но стоит людям поменяться работой и местожительством < ..> там станет так тихо, что полицейским впору будет играть в рич-рач (Генрих Бёлль. Глазами клоуна / Л.Черная. 1964);

(21) In Geschäfte der eintönigsten Art gezwungen oder vielleicht selber und freiwillig in diese Geschäfte gegangen - denn er führte sie mit einer Ordnung, mit einer Rechtlichkeit, mit einer Ausdauer, mit einer Anhänglichkeit an sie, daß man staunen mußte... (Adalbert Stifter. Der Nachsommer. 1857) -

Заваленный делами самого скучного рода или, может быть, ушедший в эти дела по собственной воле - ведь он вел их с такой аккуратностью, такой добросовестностью, с таким терпением и интересом, что впору было $\partial u$ виться... (Адальберт Штифтер. Бабье лето / С. К. Апт. 1999);

(22) Wenn Ihr so sprecht, so möcht ich nur gleich den Schwefelfaden, den ich wegwarf, wieder anzünden! (Heinrich von Kleist. Michael Kohlhaas. 1808) -

Когда я слушаю ваши речи, я жалею, что выбросил серный шнур, мне впору сейчас разыскать его и поджечь! (Генрих фон Клейст. Михаэль Кольхаас / Н. Ман. 1969).

\section{3начит $[\mathrm{P}]$}

Еще одно слово, в семантике которого неожиданным образом обнаруживается модальный смысл, — это значит. Его значение приблизительно может быть описано следующим образом: 'на основании каких-то признаков ситуации я заключаю, что должно э иметь место Р'.

(23) „Es ist praktisch einfach unmöglich, daß du Alkohol getrunken hast, du müßtest denn auch die Flasche verschluckt haben!" rief der Arzt verzweifelt aus (Friedrich Dürrenmatt. Der Verdacht. 1953) -

Однако практически это невозможно; значит, ты проглотил шнапс вместе с бутылкой! - воскликнул удивленный врач (Фридрих Дюрренматт. Подозрение / Н. Савинков. 1990);

(24) Mochte es sich damit verhalten, wie es wollte, so stand sein Entschluß, in dieser Sache auch nicht das Glied eines Fingers zu regen, fester als jemals. Man sollte sich verrechnet haben! (Thomas Mann. Buddenbrooks. 1896-1900) -

Как бы там ни было, а его решение и пальцем не шевельнуть в пользу зятя теперь еще более утвердилось. Да, значит он ошибся! (Томас Манн. Будденброки / Н. Ман. 1953). 


\section{0. Трудно [Vinf]}

Эта конструкция обозначает «смягченную невозможность». Трудно что-либо сделать - это значит 'нЕвозможно это сделать, не приложив значительных усилий’. В немецком оригинале обычно употребляется модальный глагол können с отрицанием, т. е. немецкий оригинал в большинстве встретившихся в корпусе примеров более категоричен, чем русский перевод.

(25) Dagegen könne man sich natürlich nicht wehren, denn das, was sie zwischen, vier Augen gesagt haben, ist eben auch nur zwischen vier Augen gesagt und lasse keine öffentliche Folgerung zu... (Franz Kafka. Der Prozess. 1914) -

Против этого, конечно, обороняться трудно, ведь то, что сказано с глазу на глаз, так и остается сказанным с глазу на глаз и открыто обсуждаться не может... (Франц Кафка. Процесс / Р. Райт-Ковалева. 1965);

(26) Sie war klein und ziemlich mager, sodass man beim besten Willen nicht erkennen konnte, ob sie erst acht oder schon zwölf Jahre alt war (Michael Ende. Momo. 1973);

Она была маленькая и худая, и трудно было угадать, сколько ей лет - восемь или двенадцать (Михаэль Энде. Момо / Ю. И. Коринец, 1982);

(27) „Vorgestern hatten Niederpaurs Abendgesellschaft, was wunderhübsch war, obgleich ich der Unterhaltung nicht immer folgen konnte und den Ton manchmal ziemlich équivoque fand“" (Thomas Mann. Buddenbrooks. 1896-1900) Третьего дня Нидерпауры давали вечер, очень удачный, хотя временами мне трудно было участвовать в разговоре, да и весь тон казался мне несколько équivoque (Томас Манн. Будденброки / Н. Ман. 1953).

\section{1. Никак не [Vpraes]}

В немецком оригинале здесь всегда употребляется глагол können под отрицанием. Конструкция с никак не усиливает отрицание возможности (нЕвозможно $)$. Отметим, что, судя по материалу [НКРЯ], почти в половине $(46,5 \%)$ случаев употребления никак не перед глаголом этим глаголом является мочь. В интересующей нас другой половине случаев ${ }^{6}$ никак не употребляется либо в контексте глагола со встроенным модальным компонентом (ср. никак не удается в примерах (28) и (29)), либо в контексте формы презенса совершенного вида, допускающей, с утратой некоторых смысловых компонентов, перифразу с не могу (ср. никак не пойму не могу понять), либо с нельзя, ср. никак не скажешь $\cong$ нельзя сказать ${ }^{7}$.

(28) „Es ist doch aber abscheulich, daß wir die fatale Maus nicht vertilgen können, die im Glasschrank so ihr Wesen treibt..." (Ernst Theodor Amadeus Hoffmann. Nußknacker und Mausekönig. 1816) -

\footnotetext{
6 За исключением актантного значения слова никак, ср. Этот рассказ никак не называется.

7 О значениях конструкции «никак не + praesens perfectivum» см. [Зализняк 2015б].
} 
Что за гадость, никак не удается извести мерзкую мышь, которая хозяйничает в стеклянном шкафу (Эрнст Теодор Амадей Гофман. Щелкунчик и Мышиный король / И. Татаринова. 1937);

(29) Mein Gehalt reicht zwar nie aus für einen neuen Anzug — ich kann dafür einfach das Geld nicht zusammensparen... (Erich Maria Remarque. Der schwarze Obelisk. 1956) -

На новый костюм моего жалованья, правда, не хватает - просто никак не удается скопить нужную сумму... (Эрих Мария Ремарк. Черный обелиск / В. Станевич. 1961);

(30) Da du sagst, daß auch die Familie durch den Prozeß in Mitleidenschaft gezogen würde - was ich für meinen Teil durchaus nicht begreifen kann, das ist aber Nebensache... (Franz Kafka. Der Prozess. 1914) -

Ты говоришь, что вся наша семья тоже будет втянута в процесс - правда, лично я этого никак не пойму, впрочем, это несущественно... (Франц Кафка. Процесс / Р. Райт-Ковалева. 1965);

(31) Ich kann das andere Ende nicht finden! (Michael Ende. Momo. 1973) Я никак не дойду до конца! (Михаэль Энде. Момо. Ю. И. Коринец. 1982);

(32) Wenn sie so ist, ist sie Jennie, eine mißtrauische, unangenehme Person, der man nichts recht machen kann - wenn sie anders ist, ist sie Isabelle (Erich Maria Remarque. Der schwarze Obelisk. 1956) -

Когда она такая, она - Женни, недоверчивая и несимпатичная особа, которой никак не угодишь, а когда она другая - это Изабелла (Эрих Мария Ремарк. Черный обелиск / В. Станевич. 1961);

(33) $<\ldots>$ eine ganz andere, geradezu gegenteilige, sehr körperliche, sehr materielle, die man weder als schön, noch als sinnig, noch als fromm, noch auch nur als traurig eigentlich ansprechen konnte (Thomas Mann. Der Zauberberg. 1924) $<\ldots>$ ощущение чего-то совершенно противоположного, очень материального, очень плотского, о чем никак не скажешь, что оно прекрасно, глубоко, вызывает благоговение или хотя бы скорбь (Томас Манн. Волшебная гора / В. Станевич. 1959).

\section{2. Именно [P]}

Фокусирующая частица именно и синонимичная ей (в определенном круге контекстов) частица прямо вряд ли сами по себе носители модальности, но в контексте переспроса, когда дословный перевод был бы (для примера (37)) «Это должно быть сейчас?» указывают на долженствование. Иными словами, спрашивая «Именно сейчас?» или «Прямо сейчас?», говорящий имеет в виду 'должно д ли это быть сейчас? (или можЕт дыть позже?)'.

„Jetzt? < ..> $>\boldsymbol{m} \boldsymbol{\mu} \boldsymbol{\beta}$ es jetzt sein?“ (Franz Kafka. Der Prozess. 1914) -

— Сейчас? <..> Именно сейчас? (Франц Кафка. Процесс / Р. Райт-Ковалева. 1965). 
В данной статье был предложен метод анализа, суть которого состоит в том, что неочевидные на первый взгляд семантические компоненты языковых единиц могут быть выявлены путем анализа условий их появления в переводах с другого языка, а именно с такого, где интересующий нас тип языкового значения имеет конвенциональный способ выражения. Мы использовали этот метод для выявления единиц (конструкций) русского языка с потенциально модальным значением, проанализировав способы передачи значений, выраженных в немецком оригинале конструкциями с модальными глаголами (составляющими в этом языке отчетливый семантико-грамматический класс). Относительно полученного таким образом множества конструкций русского языка - включающего, помимо безличных глаголов и предикативов, также разного рода дискурсивные слова и даже предлоги - естественно предположить, что они, по крайней мере в определенных контекстах, передают то или иное модальное значение, даже если это значение не фиксируется в словарях. Это предположение подтвердилось в ходе семантического анализа, предварительные результаты которого изложены в данной статье.

Предложенный метод может быть применен как для дальнейшего анализа конструкций с потенциально модальным значением на более обширном корпусном материале (в частности, при привлечении переводов с других языков, располагающих развитой системой средств выражения модальности), так и для выявления неочевидных семантических компонентов других типов.

\section{Литература}

Апресян Ю.Д. О Московской семантической школе // Вопросы языкознания. 2005. № 1. C. 3-30.

АС - Апресян Ю.Д., Апресян В.Ю., Бабаева Е. Э., Богуславская О. Ю., Галактионова И. В., Гловинская М. Я., Иомдин Б. Л., Крылова Т.В., Левонтина И. Б., Лопухина А.А., Птениова А.В., Санников А.В., Урысон Е.В. Активный словарь русского языка. Т. 2 : В-Г / отв. ред. акад. Ю.Д. Апресян. М. : Языки славянских культур, 2014. 736 с.

Добровольский Д. О., Зализняк Анна А. Немецкие конструкции с модальными глаголами и их русские соответствия: проект надкорпусной базы данных переводных эквивалентов // Компьютерная лингвистика и интеллектуальные технологии : сб. ст. по материалам международной конференции «Диалог-2018». Вып. 17 / гл. ред. В. П. Селегей. М. : Изд-во РГГУ, 2018. С. 172-184.

Зализняк Анна А. Многозначность в языке и способы ее представления. М. : Языки славянских культур, 2006. 672 с.

Зализняк Анна А. Лингвоспецифичные единицы русского языка в свете контрастивного корпусного анализа // Компьютерная лингвистика и интеллектуальные технологии : сб. ст. по материалам международной конференции «Диалог-2015». Вып. 14 / гл. ред. В. П. Селегей. М. : Изд-во РГГУ, 2015а. С. 651-662. 
Зализняк Анна A. Презенс совершенного вида в современном русском языке // Dekonstruktion und Konstruktion. Zwischen Sprach- und Literaturwissenschaft. Festschrift für Ulrich Schweier zum 60. Geburtstag / Hrsg. von E. Graf, I. Mendoza, B. Sonnenhauser. München ; Berlin ; Leipzig ; Wien : Kubon \& Sagner, 20156. S. 293316.

НКРЯ - Национальный корпус русского языка [Электронный ресурс]. URL: http://ruscorpora.ru

НРС - Немецко-русский словарь: актуальная лексика / под ред. Д. О. Добровольского. В печати.

Падучева E.B. Модальность // Материалы для проекта корпусного описания русской грамматики (http://rusgram.ru). M., 2016. Рукопись.

Плунгян B. A. Введение в грамматическую семантику: грамматические значения и грамматические системы языков мира. М. : Изд-во РГГУ, 2011. 672 с.

РГ 1980 - Русская грамматика : в 2 т. / гл. ред. Н. Ю. Шведова. М. : Наука, 1980.

Урысон E. В. Изменение структуры полисемии и модальных рамок слова: наречие впору в XIX веке и теперь // Русский язык в научном освещении. 2016. № 31. C. 24-61.

Bonola $A$. The parallel Italian-Russian-Italian Corpus as an Instrument for the Contrastive Study of Discourse and Textual Markers: the Case of comunque and Its Russian Translations // Съпоставително езикознание. 2017. №4. С. 89-104.

Johansson, Oksefjell 1998 - Corpora and Cross-linguistic Research: Theory, Method, and Case Studies / ed. by S. Johansson, S. Oksefjell. Amsterdam : Rodopi, 1998. 376 p.

Noël D. Translations as Evidence for Semantics: An Illustration // Linguistics. 2003. №41(4). P. 757-785.

\section{O. Dobrovol'skij', Anna A. Zalizniak²}

${ }^{1}$ Vinogradov Russian Language Institute of the Russian Academy of Sciences

Institute of Linguistics of the Russian Academy of Sciences

Stockholm University

${ }^{2}$ Institute of Linguistics of the Russian Academy of Sciences

Institute of Informatics Problems of the Federal Research Center "Computer Science and Control" of the Russian Academy of Sciences

(Russia, Moscow)

dobrovolskij@gmail.com,anna.zalizniak@gmail.com

\section{RUSSIAN CONSTRUCTIONS WITH POTENTIALLY MODAL MEANINGS: AN ANALYSIS BASED ON PARALLEL CORPUS DATA}

The present paper proposes the method of identifying Russian lexical units (constructions) with a potentially modal meaning by analyzing translational correspondences. The focus is on the ways in which the meanings expressed by German constructions with 
modal verbs are transmitted in Russian translation. German modal verbs make up a distinct semantic and grammatical class. The paper considers only the basic modal values of ontological, deontic and epistemic possibilities and necessities. The set of functional equivalents actually encountered in translated Russian texts for German constructions with modal verbs includes a number of units whose ability of expressing modal meanings is not recorded in dictionaries. The article presents a preliminary list of lexical units whose definitions contain a modal component, and provides examples of relevant crosslinguistic correspondences. The proposed method can be used both for further analysis of constructions with potentially modal meanings based on more extensive corpus data (in particular, when involving translations from other languages that have a developed system of modality expressions), and for identifying non-obvious semantic components of other types.

Key words: modality, modal meaning, Russian, German, semantics, translation.

\section{Acknowledgements}

This work was supported by RFBR grants No. 20-012-00166 and 19-012-00505.

\section{References}

Apresyan Yu.D. [On the Moscow Semantic School]. Voprosy yazykoznaniya, 2005, No. 1, pp. 3-30. (In Russ.)

Apresyan Yu.D., Apresyan V.Yu., Babaeva E.E., Boguslavskaya O.Yu., Galaktionova I. V., Glovinskaya M.Ya., Iomdin B.L., Krylova T. V., Levontina I. B., Lopukhina A. A., Ptentsova A. V., Sannikov A. V., Uryson E. V. Aktivnyi slovar' russkogo yazyka. T. 2 [Active Dictionary of the Russian Language. Vol. 2]. Yu.D. Apresyan (Ed.). Moscow, Yazyki slavyanskikh kul'tur Publ., 2014. 736 p.

Bonola A. The parallel Italian-Russian-Italian Corpus as an Instrument for the Contrastive Study of Discourse and Textual Markers: the Case of comunque and Its Russian Translations. S"postavitelno ezikoznanie, 2017, No. 4, pp. 89-104.

Corpora and Cross-linguistic Research: Theory, Method, and Case Studies. S. Johansson, S. Oksefjell (Eds.). Amsterdam, Rodopi Publ., 1998, 376 p.

Dobrovol'skij D. O., Zalizniak Anna A. [German Constructions with Modal Verbs and Their Russian Correlates: A Supracorpora Database Project]. Komp'yuternaya lingvistika i intellektual'nye tekhnologii : sb. st. po materialam mezhdunarodnoi konferentsii «Dialog-2018». Vyp. 17 [Computational Linguistics and Intellectual Technologies. Papers from the Annual International Conference Dialogue- 2018. Iss. 17]. V.P. Selegei (Ed.). Moscow, Russian St. Univ. for the Humanities Publ., 2018, pp. 172-184. (In Russ.)

Natsional'nyi korpus russkogo yazyka [Russian National Corpus]. Available at: http:// ruscorpora.ru (accessed 15.02.2020)

Nemetsko-russkii slovar': aktual'naya leksika [German-Russian Dictionary: Current Vocabulary]. D. O. Dobrovol'skij (Ed.). In print. 
Noël D. Translations as Evidence for Semantics: An Illustration. Linguistics, 2003, No. 41(4), pp. 757-785.

Paducheva E. V. [Modality]. Materialy dlya proekta korpusnogo opisaniya russkoi grammatiki (http://rusgram.ru) [The Materials for the Structural Description of Russian Grammar Project (http://rusgram.ru)]. Moscow, 2016. Manuscript. (In Russ.)

Plungyan V. A. Vvedenie v grammaticheskuyu semantiku: grammaticheskie znacheniya i grammaticheskie sistemy yazykov mira [Introduction to the Grammatical Semantics: Grammatical Meanings and Grammatical Systems in World Languages]. Moscow, Russian St. Univ. for the Humanities Publ., 2011, 672 p.

Russkaya grammatika [Russian Grammar]. (Vols. 1-2). N.Yu. Shvedova (Ed.). Moscow, Nauka Publ., 1980.

Uryson E. V. [The Change of Polysemy and Modal Frames of the Word vporu (from the Beginning of the $19^{\text {th }}$ Century until Now]. Russkii yazyk v nauchnom osveshchenii, 2016, No. 31, pp. 24-61. (In Russ.)

Zalizniak Anna A. Mnogoznachnost'v yazyke i sposoby ee predstavleniya [Polysemy and the Ways of Its Representation]. Moscow, Yazyki slavyanskikh kul'tur Publ., 2006, $672 \mathrm{p}$.

Zalizniak Anna A. [Language-Specific Russian Words in the Light of Contrastive Analysis]. Komp'yuternaya lingvistika i intellektual'nye tekhnologii : sb. st. po materialam mezhdunarodnoi konferentsii «Dialog-2015». Vyp. 14 [Computational Linguistics and Intellectual Technologies. Papers from the Annual International Conference Dialogue-2015. Iss. 14]. V. P. Selegei (Ed.). Moscow, Russian St. Univ. for the Humanities Publ., 2015a, pp. 651-662. (In Russ.)

Zaliznyik Anna A. [Praesens perfectivum in Contemporary Russian Language]. Dekonstruktion und Konstruktion. Zwischen Sprach- und Literaturwissenschaft. Festschrift für Ulrich Schweier zum 60. Geburtstag. E. Graf, I. Mendoza, B. Sonnenhauser (Hrsg.). München, Berlin, Leipzig, Wien, Kubon \& Sagner Publ., 2015b, S. 293-316. (In Russ.) 